\title{
Desempenho e Características de Carcaça de Novilhos Alimentados com Dietas Contendo Diferentes Fontes de Lipídios ${ }^{1}$
}

\section{Gabriela Aferri², Paulo Roberto Leme ${ }^{3}$, Saulo da Luz e Silva ${ }^{4}$, Soraia Marques Putrino ${ }^{4}$, Angélica Simone Cravo Pereira ${ }^{4}$}

\begin{abstract}
RESUMO - Este trabalho foi realizado para se avaliar o desempenho animal, as características da carcaça e a maciez da carne de 36 novilhos mestiços, apresentando, ao início do experimento, média de 14 meses de idade e aproximadamente 320 kg de peso vivo. Os animais foram confinados e receberam dietas com alto teor de concentrado: uma controle (CO), sem adição de lipídios; outra contendo 5\% de sais de cálcio de ácidos graxos (AG); e outra com 21\% de caroço de algodão (CA). A ingestão de matéria seca no tratamento AG foi menor que no CA, mas não diferiu da ingestão do CO. O ganho médio diário e a eficiência alimentar não apresentaram diferenças significativas entre os tratamentos. Os valores encontrados para a análise de uréia sangüínea foram significativamente maiores no tratamento CA em relação ao AG. O rendimento de carcaça, a área de olho de lombo, a espessura de gordura, as gorduras renal e pélvica, o peso do fígado, o pH e a temperatura não foram significativamente diferentes. Não houve diferença também para o índice de perda de água por cozimento e maciez, verificada pela força de cisalhamento nos diferentes tempos de maturação. Os sais de cálcio de ácidos graxos a 5\% e o caroço de algodão a $21 \%$ podem ser empregados nas rações para confinamento, sem causarem alterações no desempenho animal ou nas características de carcaça.
\end{abstract}

Palavras-chave: características de carcaça, caroço de algodão, confinamento, espessura de gordura, rendimento de carcaça, sais de cálcio de ácidos graxos

\section{Performance and Carcass Characteristics of Steers Fed Different Fat Sources}

\begin{abstract}
The objective of this trial was to evaluate the animal performance, carcass characteristics and meat tenderness of 36 crossbred steers averaging 14 months old and $320 \mathrm{~kg}$ body weight. The animals were fed high concentrate-based diets: control - without additional fat (CO); diet with 5\% calcium salt of fatty acids (AG); and diet with 21\% whole cottonseed (CA). Dry matter intake of AG treatment was lower $(\mathrm{P}=0,05)$ than $\mathrm{CA}$, that differ from CO diet. No significant differences of treatments on daily weight gain and feed efficiency were observed. Blood urea nitrogen was greater $(\mathrm{P}=0,01)$ for $\mathrm{CA}$ treatment than $\mathrm{AG}$ treatment. Carcass dressing, rib eye area, fat thickness, kidney and pelvic fat, liver weight, pH and temperature did not show significant difference. No difference on water loss during cooking and tenderness measured by shear force at different aging times was detected. Diets with $5 \%$ calcium salt of fatty acids or $21 \%$ whole cottonseed can be used for feedlot with no change on animal performance or carcass characteristics.
\end{abstract}

Key Words: calcium salt of fatty acids, carcass dressing, fat thickness, feedlot, rib eye area, whole cottonseed

\section{Introdução}

A gordura é um nutriente fundamental e também importante componente do sistema de produção de carne, pois a eficiência de produção, a precocidade, o acabamento da carcaça, os rendimentos de cortes, a maciez e a suculência do produto estão relacionados à quantidade e ao local de deposição de gordura (Berndt et al., 2002). Os lipídios ou gorduras são compostos de ácidos graxos, pertencentes, em grande número, a dois grupos: o dos ácidos graxos insaturados e dos ácidos graxos saturados. O estado de saturação ou não-saturação é uma importante característica química e nutricional (Franco, 2001). Há indícios de que o tipo de dieta fornecida ao animal altera a composição de lipídios da carcaça e do leite de bovinos, o que permitiria manipular a composição da fração gordurosa com o uso, por exemplo, de sementes oleaginosas (French et al., 2000).

Os óleos e as gorduras são amplamente utilizados na alimentação animal (Andriguetto et al., 1988). Nos ruminantes, a gordura tem grande influência sobre o equilíbrio ruminal, reduzindo a atividade de microrganismos celulolíticos (Ezequiel, 2001). O fornecimento de altos níveis de gordura na dieta pode causar problemas de absorção de nutrientes, pois os ácidos

\footnotetext{
1 Projeto financiado pela Fapesp.

${ }^{2}$ Doutoranda - Faculdade de Zootecnia e Engenharia de Alimentos (FZEA) - Universidade de São Paulo (USP), Caixa Postal 23, Pirassununga/SP. E.mail: aferri@netsite.com.br

3 Professor Livre Docente - FZEA - USP.

${ }^{4}$ Aluno de Doutorado - FZEA - USP.
} 
graxos reduzem o pH do rúmen e, conseqüentemente, alteram a flora ruminal. A gordura também diminui a digestibilidade da forragem, pelo efeito tóxico dos ácidos graxos de cadeia longa sobre as bactérias ruminais (Henderson, 1973), além de prejudicar a palatabilidade Johnson \& McLure (1973). Uma alternativa para se reduzir os problemas metabólicos dos alimentos ricos em gordura seria o fornecimento de gordura protegida da biohidrogenação ruminal, que não influencia o processo digestivo ruminal, sendo dissolvida e absorvida no intestino delgado.

Os estudos sobre metabolismo lipídico no rúmen têm se concentrado principalmente na manipulação dos fenômenos físico-químicos do rúmen, com dois objetivos: controlar os efeitos antimicrobianos dos ácidos graxos, de forma que a gordura adicional possa ser empregada na alimentação de ruminantes sem prejuízo da digestão e da fermentação ruminal; e regular a biohidrogenação microbiana, para controle da absorção de determinados ácidos graxos que podem promover a performance ou reduzir a saturação da gordura da carne e do leite (Jenkins, 1993). Beam et al. (2000) destacam que o rúmen é um obstáculo a ser transposto pelos ácidos graxos insaturados para que possam ser digeridos e absorvidos no intestino delgado. Segundo Duckett (2003) a proteção da gordura pode resultar da formação de complexos de ácidos graxos com sais de cálcio, da proteção com proteína protegida, que tornam a gordura indisponível quimicamente para a biohidrogenação ruminal, ou das sementes oleaginosas, que são fisicamente protegidas da biohidrogenação pelas cascas de suas sementes. $\mathrm{O}$ conteúdo de óleo das forragens e de vários grãos, embora seja usualmente baixo, possui altas proporções de ácidos graxos polinsaturados, em particular os ácidos linolênico e linoléico (Tume, 2003). Coppock \& Wilks (1991), citados por Ruy et al. (1996), afirmaram que o fornecimento de lipídios provenientes de sementes oleaginosas compreende uma liberação lenta do óleo no decorrer do dia, decorrente da regurgitação e remastigação das sementes, permitindo a ação dos microrganismos ruminais em hidrogenar as ligações duplas dos ácidos graxos insaturados, impedindo o efeito inibidor do óleo sobre a digestibilidade da fibra.

O objetivo neste trabalho foi avaliar o efeito da adição de óleo vegetal protegido da degradação ruminal ou de caroço de algodão em dietas com alto teor de concentrado sobre o desempenho e as características de carcaça de novilhos confinados.

\section{Material e Métodos}

Foram utilizados 36 animais machos castrados, aproximadamente $3 / 4$ Bos taurus taurus, filhos de vacas cruzadas Simental x Nelore com touros Brangus, com idade e peso vivo médios iniciais de 14 meses e $320 \mathrm{~kg}$, respectivamente. Os animais foram distribuídos aleatoriamente em três tratamentos, com 12 cada, e alojados em 18 baias parcialmente cobertas e de piso cimentado, com cocho e bebedouro automático. Os tratamentos foram compostos por três dietas com $19 \%$ de cana-de-açúcar como volumoso e $81 \%$ de concentrado, sendo uma ração com $5 \%$ de sais de cálcio de ácidos graxos, outra com $21 \%$ de caroço de algodão e a ração controle sem fonte adicional de lipídios.

Os animais foram submetidos a um período de 28 dias de adaptação à dieta e 86 dias de confinamento. As rações foram formuladas com auxílio do programa Ração de Lucro Máximo - $\left(\right.$ RLM $\left.^{\circledR}\right)$ da ESALQ-USP e balanceadas de acordo com o Cornell Net Carboydrate and Protein System (CNCPS), desenvolvido por Fox et al. (1992). As rações completas (Tabela 1) foram fornecidas à vontade uma vez ao dia, pela manhã.

As sobras dos alimentos foram pesadas duas vezes por semana, coletando-se amostras para determinação dos teores de matéria seca. O ajuste do fornecimento de ração foi diário, considerando-se os valores das sobras. Em cada período de 28 dias, foram colhidas amostras de ração e da cana-de-açúcar, para análise bromatológica (Tabela 2), feita de acordo com a metodologia de Weende (Silva, 1998), exceto para a ração com gordura protegida, que seguiu a metodologia de Medeiros (2002).

Aproximadamente a cada 28 dias, após jejum completo de 18 horas, os animais foram pesados e examinados por ultra-som, obtendo-se imagens para determinação da espessura de gordura subcutânea (EGSU) e da área de olho de lombo (AOLU) entre a $12^{\mathrm{a}}$ e $13^{\mathrm{a}}$ costelas. Também foram coletadas amostras de sangue dos animais, para o cálculo do teor de nitrogênio uréico (NUS), aproximadamente na metade do período experimental. O teor de uréia no soro foi obtido utilizando-se kits comerciais da marca Laborlab ${ }^{\circledR}$. Os valores de uréia foram multiplicados por 0,466, para se obter o nitrogênio no plasma (NUP) em mg/dL (Putrino, 2002). Para obtenção do valor de nitrogênio da uréia sanguínea (NUS), em mg/dL, a partir do NUP, foi utilizada a equação de regressão de Broderick \& Clayton (1997). 
Tabela 1 - Rações experimentais (\% MS)

Table 1 - Experimental diets (\% DM)

\begin{tabular}{|c|c|c|c|}
\hline $\begin{array}{l}\text { Ingrediente } \\
\text { Ingredient }\end{array}$ & $\mathrm{AG}^{3}$ & $\mathrm{CA}^{4}$ & $\mathrm{CO}^{5}$ \\
\hline $\begin{array}{l}\text { Cana-de-açúcar } \\
\text { (planta inteira) } \\
\text { Sugar cane (whole plant) }\end{array}$ & 19,00 & 19,00 & 19,00 \\
\hline $\begin{array}{l}\text { Farelo de soja (49\%) } \\
\text { Soybean meal }\end{array}$ & 14,00 & 9,00 & 12,50 \\
\hline $\begin{array}{l}\text { Milho grão seco } \\
\text { Corn, ground }\end{array}$ & 26,54 & 21,18 & 29,36 \\
\hline $\begin{array}{l}\text { Polpa cítrica } \\
\text { Citrus pulp }\end{array}$ & 33,61 & 26,82 & 37,19 \\
\hline LAC $100^{\circledR}$ & 5,00 & - & - \\
\hline $\begin{array}{l}\text { Caroço de algodão } \\
\text { Cottonseed, whole }\end{array}$ & - & 21,00 & - \\
\hline $\begin{array}{l}\text { Uréia } \\
\text { Urea }\end{array}$ & 0,85 & 0,50 & 0,95 \\
\hline $\begin{array}{l}\text { Calcário } \\
\text { Limestone }\end{array}$ & - & 1,50 & - \\
\hline $\begin{array}{l}\text { Sal mineral } \\
\text { Mineral salt }\end{array}$ & 1,00 & 1,00 & 1,00 \\
\hline $\begin{array}{l}\text { Rumensin }{ }^{\circledR} \\
\text { Nutrientes } \\
\text { Nutrients }\end{array}$ & 0,027 & 0,027 & 0,027 \\
\hline $\begin{array}{l}\text { Proteína bruta, \% } 1 \\
\text { Crude protein }\end{array}$ & 14,40 & 14,22 & 14,44 \\
\hline $\begin{array}{l}\text { Proteína degradável } \\
\text { no rúmen, } \%^{1} \\
\text { Rumen degradable protein }\end{array}$ & 9,89 & 9,52 & 9,99 \\
\hline $\begin{array}{l}\text { NDT, } \%^{2} \\
\text { TDN }\end{array}$ & 81,98 & 77,89 & 77,11 \\
\hline \multicolumn{4}{|c|}{$\begin{array}{l}\left.{ }^{1} \text { Estimada pelo programa } \mathrm{RLM}^{\circledR} \text { (Estimated by } R L M^{\circledR}\right) \text {. } \\
{ }^{2} \text { Estimado pela fórmula de Weiss et al. (1992) (Estimated by Weiss } \\
\text { et al. [1992] formula). } \\
{ }^{3} \mathrm{AG}-\text { Sais de cálcio de ácidos graxos (AG - calcium salt of fatty } \\
\text { acids). } \\
{ }^{4} \mathrm{CA}-\text { Caroço de algodão (CA - whole cottonseed). } \\
{ }^{5} \text { CO Controle (CO without any additional fat). }\end{array}$} \\
\hline
\end{tabular}

Ao final do período experimental, os animais foram abatidos. Durante o abate, foram obtidos os pesos de carcaça quente (PCQ), do fígado (PFIG) e das gorduras renal e pélvica (GRP), além do $\mathrm{pH}(\mathrm{pH} 1)$ e da temperatura (TEMP1) das carcaças uma hora após o abate. Posteriormente, as carcaças foram colocadas em câmara frigorífica com temperatura de 0 a $1^{\circ} \mathrm{C}$. Vinte e quatro horas após o abate, foram obtidos o peso da carcaça fria (PCF), o pH (pH24) e a temperatura (TEMP24) das carcaças. As meia-carcaças esquerdas foram seccionadas entre a $12^{\mathrm{a}}$ e $13^{\mathrm{a}}$ costelas, para determinação da área de olho de lombo (AOLC) e da espessura de gordura subcutânea (EGSC), utilizando-se uma grade reticulada própria, com medida em centímetros quadrados $\left(\mathrm{cm}^{2}\right)$.

Três amostras do contra-filé (Longissimus dorsi) de aproximadamente $2,5 \mathrm{~cm}$ de espessura foram retiradas, embaladas a vácuo e maturadas por 0, 7 ou 14 dias, para posterior determinação das perdas por cozimento e da força de cisalhamento (Warner Bratzler).

O delineamento experimental utilizado foi o inteiramente casualizado, com três tratamentos e seis repetições. As análises estatísticas foram feitas usando o programa SAS (1989). Para o estudo do desempenho e das características de carcaça, foi utilizado o seguinte modelo matemático:

$$
\text { Yij }=\mu+\mathrm{Ti}+\mathrm{eij}
$$

em que Yij = j-ésima observação referente ao j-ésimo tratamento; $\mu$ = média geral; $\mathrm{Ti}=$ efeito do i-ésimo tratamento; eij = erro inerente a cada observação $\operatorname{NID}\left(0, \sigma_{\mathrm{e}}^{2}\right)$

Tabela 2 - Análise bromatológica dos concentrados e da cana-de-açúcar (\% MS)

Table 2 - Chemical composition of concentrates and sugar cane (\%DM)

\begin{tabular}{|c|c|c|c|c|c|c|c|c|}
\hline $\begin{array}{l}\text { Amostra } \\
\text { Sample }\end{array}$ & $\begin{array}{l}\text { MS } \\
D M\end{array}$ & $\begin{array}{l}\mathrm{PB} \\
C P\end{array}$ & $\begin{array}{l}\mathrm{FB} \\
C P\end{array}$ & $\begin{array}{c}\mathrm{EE} \\
M M\end{array}$ & $\begin{array}{l}\mathrm{MM} \\
\text { NFE }\end{array}$ & $\begin{array}{l}\text { ENN } \\
N D F\end{array}$ & $\begin{array}{l}\text { FDN } \\
A D F\end{array}$ & FDA \\
\hline $\begin{array}{l}\text { Sais de cálcio de ácidos graxos } \\
\text { Calcium salt of fatty acids }\end{array}$ & 91,26 & 17,17 & 8,16 & 6,00 & 7,37 & 63,15 & - & - \\
\hline $\begin{array}{l}\text { Caroço de algodão } \\
\text { Cottonseed, whole }\end{array}$ & 91,59 & 19,28 & 13,08 & 8,25 & 6,20 & 54,32 & - & - \\
\hline $\begin{array}{l}\text { Controle } \\
\text { Control }\end{array}$ & 90,33 & 18,23 & 7,16 & 2,96 & 6,17 & 64,99 & - & - \\
\hline $\begin{array}{l}\text { Cana-de-açúcar } \\
\text { Sugar cane }\end{array}$ & 27,84 & 2,46 & 26,59 & 0,59 & 1,97 & 68,70 & 57,30 & 38,09 \\
\hline
\end{tabular}




\section{Resultados e Discussão}

As médias, os coeficientes de variação (CV) e as probabilidades (P) das características de desempenho estão dispostos na Tabela 3.

Não foram observadas diferenças significativas entre os tratamentos quanto ao peso final e ao ganho médio diário (Tabela 3). A ingestão de matéria seca foi menor para o tratamento com sais de cálcio de ácidos graxos $(\mathrm{P}<0,05)$ em relação ao caroço de algodão.

Os resultados verificados neste trabalho são semelhantes aos encontrados por Sutter et al. (2000), que constataram que a ingestão de matéria seca de tourinhos Pardo-Suíço alimentados com gordura protegida (4,7\% da MS) foi menor que naqueles do tratamento controle e não alterou o ganho de peso. O tratamento com caroço de algodão não apresentou ganho de peso diário e ingestão de matéria seca diferentes do tratamento controle. Resultados semelhantes também foram verificados por Prado et al. (1995), que avaliaram o desem- penho de novilhos Nelore confinados com dois níveis de caroço de algodão na dieta (15 ou 30\% da MS), associados à cana-de-açúcar ou capim-elefante, e não constataram diferença entre os tratamentos, tanto para ganho de peso diário como para ingestão diária de matéria seca.

A eficiência e a conversão alimentar também não diferiram entre os tratamentos. No entanto, trabalhos com diferentes fontes de gordura indicaram que a conversão e a eficiência alimentar são melhoradas quando a dieta contém níveis elevados de lipídios. Avaliando a conversão alimentar de dietas com ausência ou com inclusão de 2, 4 ou 6\% de gordura protegida na dieta, Ngidi et al. (1990) observaram tendência de melhora para os níveis mais elevados. A conversão e a eficiência alimentar com o uso de caroço de algodão não diferiram do tratamento controle, de forma semelhante aos resultados encontrados por Moletta (1999), que utilizou silagem de milho e concentrado com $20 \%$ de grão de soja ou caroço de algodão.

Tabela 3 - Valores dos pesos inicial e final, ganho médio diário, ingestão de matéria seca, em quilos por dia (kg/d), em porcentagem do peso vivo (\% PV) e em gramas por quilo de peso metabólico (g/kg0,75), eficiência (g GMD/ $\mathrm{kg} \mathrm{MSI})$ e conversão alimentar (kg MSI/kg GMD) e valores de uréia sangüínea

Table 3 - Values of initial and final weights, average daily weight gain, dry matter intake ( $\mathrm{kg} / \mathrm{d}$, \%BW and g/kg $\left.{ }^{0.75}\right)$, feed efficiency and feed:gain ratio and blood urea

\begin{tabular}{|c|c|c|c|c|c|}
\hline \multirow[t]{2}{*}{$\begin{array}{l}\text { Característica } \\
\text { Characteristic }\end{array}$} & \multicolumn{3}{|c|}{$\begin{array}{l}\text { Tratamento } \\
\text { Treatment }\end{array}$} & \multirow[t]{2}{*}{ CV (\%) } & \multirow[t]{2}{*}{$\mathrm{P}$} \\
\hline & $\mathrm{AG}$ & CA & $\mathrm{CO}$ & & \\
\hline $\begin{array}{l}\text { Número de animais } \\
\text { Number of animals }\end{array}$ & 12 & 12 & 12 & - & - \\
\hline $\begin{array}{l}\text { Peso vivo inicial, } \mathrm{kg} \\
\text { Initial weight }\end{array}$ & 354 & 348 & 362 & 9,7 & 0,69 \\
\hline $\begin{array}{l}\text { Peso vivo final, kg } \\
\text { Final weight }\end{array}$ & 430 & 428 & 444 & 8,7 & 0,54 \\
\hline $\begin{array}{l}\text { Ganho médio diário, kg } \\
\text { Average daily gain }\end{array}$ & 1,107 & 1,169 & 1,204 & 24,5 & 0,70 \\
\hline $\begin{array}{l}\text { Ingestão de matéria seca, } \mathrm{kg} / \mathrm{d} \\
\text { Dry matter intake }\end{array}$ & $8,12^{\mathrm{b}}$ & $9,49^{\mathrm{a}}$ & $9,20^{\mathrm{ab}}$ & 14,8 & 0,04 \\
\hline $\begin{array}{l}\text { Ingestão de matéria seca, \%PV } \\
\text { Dry matter intake }(\% L W)\end{array}$ & $2,08^{\mathrm{b}}$ & $2,45^{\mathrm{a}}$ & $2,29^{\mathrm{ab}}$ & 13,0 & 0,02 \\
\hline $\begin{array}{l}\text { Ingestão de matéria seca, } \mathrm{g} / \mathrm{kg}^{0,75} \\
\text { Dry matter intake }\left(\mathrm{g} / \mathrm{kg}^{0.75}\right)\end{array}$ & $92^{\mathrm{b}}$ & $108^{\mathrm{a}}$ & $102^{\mathrm{ab}}$ & 12,8 & 0,02 \\
\hline $\begin{array}{l}\text { Eficiência alimentar, g GMD/kg MS } \\
\text { Feeding efficiency }\end{array}$ & 136,48 & 123,89 & 131,05 & 22,3 & 0,57 \\
\hline $\begin{array}{l}\text { Conversão alimentar, kg MS/kg GMD } \\
\text { Feed:gain, ratio }\end{array}$ & 8,03 & 8,38 & 7,86 & 27,6 & 0,85 \\
\hline $\begin{array}{l}\text { Uréia sangüínea, mg/dL } \\
\text { Blood urea }\end{array}$ & $11,44^{b}$ & $18,36^{\mathrm{a}}$ & $12,37^{\mathrm{ab}}$ & 23,8 & 0,01 \\
\hline
\end{tabular}

$\mathrm{a}, \mathrm{b}$ Letras diferentes na mesma linha indicam diferença significativa.

$a, b$ Different characters with the same superscript differ. 
Os valores de nitrogênio originário da uréia sangüínea observados para o tratamento com caroço de algodão foram maiores que os do tratamento com sais de cálcio de ácidos graxos $(\mathrm{P}<0,01)$, que não diferiu do tratamento controle. Segundo Swenson \& Reece (1996) estes valores estão dentro do considerado normal para bovinos, que varia de 10 a $30 \mathrm{mg} / \mathrm{dL}$. Hamond et al. (1993), citados por Putrino (2002), afirmam que o NUS é utilizado como indicativo do balanço protéico, sendo que os limites que indicam a adequada ingestão protéica são de 9 a 12 mg/dL. Valadares et al. (1997) concluíram que a concentração plasmática de nitrogênio da uréia de 13,52 a 15,15 mg/dL correspondeu à máxima eficiência microbiana e provavelmente representaria o limite a partir do qual ocorre perda de proteína para novilhos zebuínos alimentados com rações contendo $45 \%$ de concentrados e, em média, 62,5\% de NDT. Neste trabalho com valores muito próximos de proteína bruta e proteína degradável no rúmen na formulação dos três tratamentos, os valores de NUS que estiveram dentro do intervalo considerado normal para bovinos (Swenson \& Reece, 1996) excederam os limites considerados adequados para a ingestão protéica (Valadares et al., 1997; Putrino, 2002) apenas no tratamento com caroço de algodão. Uma possível explicação para esta alteração seria que o óleo do caroço de algodão poderia reduzir a fermentação ruminal, com maior escape de nitrogênio para a corrente sangüínea. Valinote et al. (2003) constata- ram severa diminuição na população de protozoários de novilhos Nelore alimentados com a mesma dieta de caroço de algodão deste trabalho, o que sustenta esta hipótese. Na análise dos parâmetros ruminais deste experimento, Salles et al. (2003) observaram que os resultados de $\mathrm{pH}$, concentração de ácidos graxos voláteis totais, porcentagem de ácidos acético, propiônico e butírico, proporção de ácido acético em relação ao ácido propiônico e concentração de nitrogênio amoniacal no líquido ruminal não apresentaram diferenças entre os tratamentos. A dieta com caroço de algodão, embora tenha ocasionado uma elevação do nível de NUS e redução da população microbiana, não ocasionou distúrbios ruminais graves e conseqüente queda do desempenho.

As médias, os coeficientes de variação (CV) e as probabilidades $(\mathrm{P})$ das características quantitativas das carcaças estão contidos na Tabela 4.

Não foram observadas diferenças significativas entre as características de carcaça analisadas (Tabela 4). O rendimento de carcaça apresentou valores homogêneos, não havendo diferença significativa entre os tratamentos. Resultados semelhantes foram relatados por Sutter et al. (2000), que não observaram diferença significativa no rendimento de carcaça de tourinhos Pardo-Suíço alimentados com dietas contendo $4,7 \%$ de gordura em relação àqueles que receberam dieta sem gordura. Segundo Moletta (1999) animais mestiços Canchim não apresentaram diferença no rendimento de carcaça quando foram

Tabela 4 - Peso da carcaça quente e fria, rendimento de carcaça, pesos da gordura renal e pélvica e do fígado, área de olho de lombo e espessura de gordura subcutânea (AOL/100 kg e EGS/100 kg)

Table 4 - Values of hot and cold carcass weight, dressing percentage, weights of kidney and pelvic fat and of liver, rib eye area and backfat thickness $/ 100 \mathrm{~kg}$

\begin{tabular}{|c|c|c|c|c|c|}
\hline \multirow[t]{2}{*}{$\begin{array}{l}\text { Característica } \\
\text { Characteristic }\end{array}$} & \multicolumn{3}{|c|}{$\begin{array}{c}\text { Tratamento } \\
\text { Treatment }\end{array}$} & \multirow[t]{2}{*}{ CV $(\%)$} & \multirow[t]{2}{*}{$\mathrm{P}$} \\
\hline & AG & CA & $\mathrm{CO}$ & & \\
\hline Peso da carcaça quente, kg (Hot carcass weight) & 244 & 242 & 250 & 9,2 & 0,71 \\
\hline Rendimento carcaça quente, \% (Hot dressing percentage) & 56,6 & 56,6 & 56,3 & 2,4 & 0,81 \\
\hline Peso da carcaça fria, kg (Cold carcass weight) & 240 & 239 & 246 & 9,3 & 0,71 \\
\hline Rendimento carcaça fria, \% (Cold dressing percentage) & 55,7 & 55,8 & 55,5 & 2,5 & 0,82 \\
\hline Área do olho lombo, $\mathrm{cm}^{2}$ (Rib eye area) & 71,5 & 66,9 & 66,9 & 12,8 & 0,34 \\
\hline Espessura gordura subcutânea, mm (Backfat thickness) & 5,3 & 5,3 & 5,5 & 34,5 & 0,97 \\
\hline Área olho lombo/100 kg, cm² (Rib eye area/100 kg) & 29,8 & 28,0 & 27,2 & 10,3 & 0,08 \\
\hline Espessura gordura/100 kg, mm (Backfat thickness/100 kg) & 2,2 & 2,2 & 2,2 & 32,8 & 0,99 \\
\hline Gordura renal e pélvica, kg (Kidney and pelvic fat) & 9,7 & 9,6 & 9,4 & 27,6 & 0,97 \\
\hline Peso do fígado, kg (Liver weight) & 5,6 & 5,2 & 5,5 & 10,8 & 0,34 \\
\hline
\end{tabular}


alimentados com soja grão ou caroço de algodão, ambos fornecidos na proporção de $20 \%$ do concentrado. Estes valores estão de acordo com os observados neste experimento. Da mesma forma, Paulino et al. (2002), trabalhando com animais mestiços (Holandês X Nelore) suplementados a pasto com caroço de algodão, farelo de soja ou soja em grão, não observaram diferença entre os tratamentos quanto ao peso e rendimento da carcaça quente.

Os valores encontrados para área de olho de lombo por 100 quilogramas de peso de carcaça ficaram próximos do mínimo necessário, que, de acordo com Luchiari Filho (2000), é de $29 \mathrm{~cm}^{2}$, e a espessura de gordura subcutânea acima de $5 \mathrm{~mm}$, como foi observado. As medidas da área de olho de lombo e de gordura subcutânea não apresentaram valores significativamente diferentes entre os tratamentos, quando medidas diretamente na carcaça ou em relação a 100 kg de carcaça. Isto também foi constatado por Ngidi et al. (1990), que observaram que o uso de sais de cálcio de ácidos graxos nos níveis de 0 até $6 \%$ da matéria seca, para engorda de novilhos, não influenciou a espessura de gordura da carcaça ou a área de olho de lombo. Resultado semelhante foi observado por Zinn et al. (2000), que alimentaram novilhos holandeses com dietas de sais de cálcio de ácidos graxos e gordura animal, até o nível de $6 \%$ e concluíram que estas dietas não tiveram efeito sobre a área de olho de lombo ou sobre a gordura subcutânea.

Não houve diferenças significativas entre os tratamentos quanto à gordura renal e pélvica e ao peso do fígado. Segundo Luchiari Filho (2000), a gordura renal e pélvica tem sido utilizada como indicador do rendimento dos cortes com um coeficiente de correlação negativo. Neste sentido, o uso de sais de cálcio de ácidos graxos ou de caroço de algodão não exerceu influência sobre o rendimento dos cortes cárneos. Em estudo com novilhos Brangus alimentados com 30\% de caroço de algodão, Page et al. (1997) encontraram aumento no peso do fígado e na gordura renal, pélvica e cardíaca diferente do que foi observado neste estudo. Segundo os autores, o aumento na espessura de gordura subcutânea sem aumento na área de olho de lombo demonstra que a adição de caroço de algodão aumentou a deposição de gordura.

Não foi observada interação entre os efeitos de tratamento e de tempo das medidas de ultra-som tanto para área de olho de lombo (Figura 1) quanto para espessura de gordura subcutânea (Figura 2). Houve efeito apenas do tempo de medida. Tanto a área de

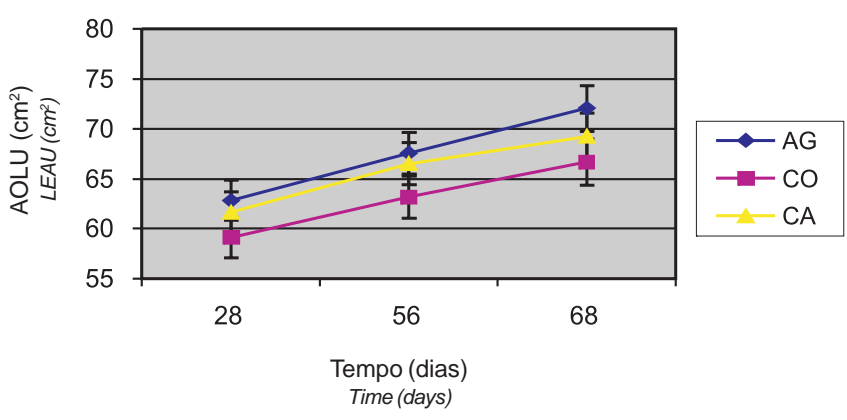

Figura 1 - Gráfico da área de olho de lombo (AOLU) obtida por ultra-som $\left(\mathrm{cm}^{2}\right)$, em função do tempo (dias de confinamento) para os tratamentos controle (CO) com sais de cálcio de ácidos graxos (AG) e caroço de algodão (CA).

Figure 1 - Graphic of rib eye area (LEAU) measured by ultrasound $\left(\mathrm{cm}^{2}\right) \times$ time (feedlot days) for treatments: calcium salt of fatty acids (AG), control (CO) and whole cottonseed (CA).

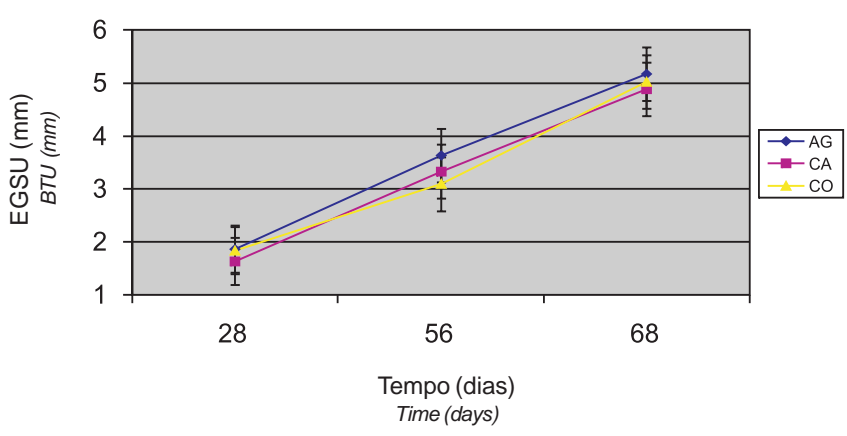

Figura 2 - Gráfico da espessura de gordura subcutânea (EGSU) obtida por ultra-som (mm), em função do tempo (dias de confinamento), para os tratamentos com sais de cálcio de ácidos graxos (AG), caroço de algodão (CA) e controle (CO).

Figure 2 - Graphic of backfat thickness (BTU) measured by ultrasound $(\mathrm{mm}) \times$ time (feedlot days) for treatments: calcium salt of fatty acids (AG), control (CO) and whole cottonseed (CA).

olho de lombo quanto a espessura de gordura subcutânea aumentaram linearmente $(\mathrm{P}<0,01)$. Resultados semelhantes foram observados por Silva et al. (2002), ao trabalharem com novilhos Nelore alimentados com dietas contendo altos níveis de concentrado.

Médias, coeficientes de variação (CV) e probabilidades (P) das características qualitativas das carcaças estão contidos na Tabela 5.

Os valores de $\mathrm{pH}$ e temperatura, tanto na primeira hora como 24 horas após o abate, não foram significativamente diferentes Os valores encontrados estão dentro do esperado, que devem ser de 5,5 a 5,8 para 
Desempenho e Características de Carcaça de Novilhos Alimentados com Dietas Contendo Diferentes...

Tabela 5 - Temperatura 1 e 24 horas após o abate, pH 1 e 24 horas após o abate e perda por cozimento para 1 , 7 e 14 dias após o abate

Table 5 - Temperature 1 and 24 hours post slaughter, pH 1 and 24 hours post slaughter and cooking loss for 1,7 and 14 days post slaughter

\begin{tabular}{|c|c|c|c|c|c|}
\hline \multirow[t]{2}{*}{$\begin{array}{l}\text { Característica } \\
\text { Characteristic }\end{array}$} & \multicolumn{3}{|c|}{$\begin{array}{c}\text { Tratamento } \\
\text { Treatment }\end{array}$} & \multirow[t]{2}{*}{ CV (\%) } & \multirow[t]{2}{*}{$\mathrm{P}$} \\
\hline & AG & CA & $\mathrm{CO}$ & & \\
\hline Temperatura 1 hora, ${ }^{\circ} \mathrm{C}$ (Temperature 1 hour) & 37,53 & 36,61 & 36,82 & 4,1 & 0,30 \\
\hline Temperatura 24 horas, ${ }^{\circ} \mathrm{C}$ (Temperature 24 hours) & 3,13 & 2,98 & 3,60 & 26,2 & 0,18 \\
\hline pH 1 hora (pH 1 hour) & 6,48 & 6,56 & 6,61 & 2,6 & 0,20 \\
\hline pH 24 horas (pH 24 hours) & 5,52 & 5,54 & 5,63 & 3,9 & 0,51 \\
\hline Perda por cozimento 1 dia, \% (Cooking loss 1 day) & 19,67 & 16,98 & 19,64 & 22,8 & 0,22 \\
\hline Perda por cozimento 7 dias, \% (Cooking loss 7 days) & 17,67 & 15,99 & 16,41 & 26,0 & 0,63 \\
\hline Perda por cozimento 14 dias, \% (Cooking loss 14 days) & 16,61 & 18,14 & 15,3 & 20,1 & 0,14 \\
\hline
\end{tabular}

o pH na $24^{\mathrm{a}}$ hora post mortem (Felício, 1997; Luchiari Filho, 2000) e menor que $5^{\circ} \mathrm{C}$ para a temperatura da carcaça (Felício, 1997).

Estudando o efeito de dias em confinamento em novilhos Angus x Hereford, May et al. (1992) constataram que o $\mathrm{pH}$ muscular na $24^{\mathrm{a}}$ hora tendeu a ser maior para novilhos abatidos no início do experimento. As carcaças dos animais que não ficaram em confinamento apresentaram valores de $\mathrm{pH}$ na $24^{\mathrm{a}}$ hora maiores que as dos animais com 84 dias ou mais de confinamento e alimentados com dieta contendo altos níveis de energia. O índice de perda por cozimento não resultou em diferenças significativas para os tratamentos, o mesmo ocorrendo na análise de maciez, medida pela força de cisalhamento nos diferentes tempos de maturação. No entanto, o tratamento controle tendeu $(\mathrm{P}=0,08)$ a ser mais macio com 7 dias de maturação (Figura 3).

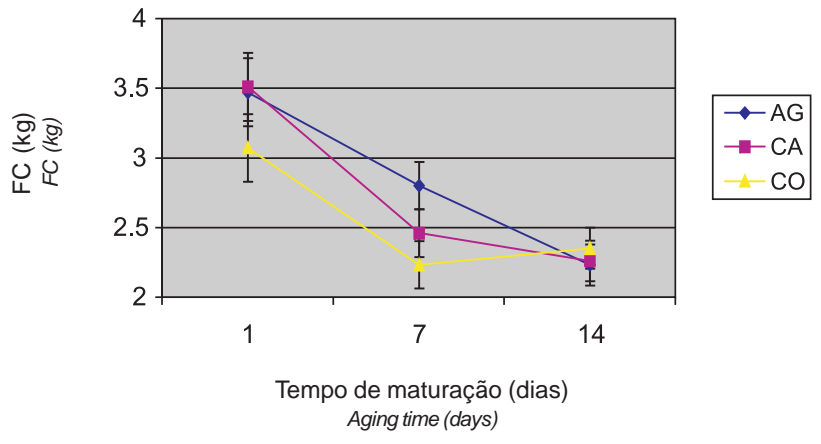

Figura 3 - Gráfico da força de cisalhamento (FC) (kg), em função do tempo de maturação (dias).

Figure 3 - Graphic of shear force (FC) $x$ aged (days).
Os valores de 3,0 a $3,5 \mathrm{~kg}$ encontrados neste trabalho estão aquém do limite de 3,8 kg, proposto por Forrest et al. (1975) para o músculo Longissimus, indicando carne muito macia, que ainda pode ser melhorada com a maturação por 14 dias.

\section{Conclusões}

A inclusão de sais de cálcio de ácidos graxos em dietas com elevada proporção de concentrado (81\%) para novilhos em confinamento decresceu a ingestão de matéria seca em relação à dieta com caroço de algodão, mas não teve efeito sobre o desempenho. A inclusão, tanto da gordura protegida quanto do caroço de algodão, também não modificou as características de carcaça e de maciez da carne, em relação à dieta controle.

\section{Literatura citada}

ANDRIGUETTO, J.M. Nutrição animal: as bases e os fundamentos da nutrição animal: os alimentos. São Paulo: Nobel, 1988. v.1. 395p.

BEAM, T.M.; JENKINS, T.C.; MOATE, P.J. et al. Effects of amount and source of fat on the rates of lipolysis and biohydrogenation of fatty acids in ruminal contents. Journal of Dairy Science, v.83, p.2564-2573, 2000.

BERNDT, A.; ALMEIDA, R.; LANNA, D.P. Importância da gordura na eficiência de produção, qualidade da carne e saúde do consumidor. In: ENCONTRO NACIONAL DO NOVILHO PRECOCE, 7., 2002, Cuiabá. Anais... Cuiabá: 2002.1 CD.

BRODERICK, G.A.; CLAYTON, M.K. A statistical evaluation of animal and nutritional factors influencing concentrations of milk urea nitrogen. Journal of Dairy Science, v.80, n.11, p.2964-2971, 1997. 
DUCKETT, S.K. Effect of nutrition and management practices on marbling deposition and composition. Disponível em: http://www.cabprogram.com/cabprogram/sd/ articles/duckett.html. Acesso em: 04 fev. 2003.

EZEQUIEL, J.M.B. Uso de caroço de algodão na alimentação animal. In: SIMPÓSIO GOIANO SOBRE MANEJO E NUTRIÇÃO DE BOVINOS, 3., 2001, Goiânia. Anais... Goiânia: Colégio Brasileiro de Nutrição Animal, 2001. p.307-328.

FELÍCIO, P.E. Fatores ante e post mortem que influenciam na qualidade da carne bovina. In: SIMPÓSIO SOBRE PECUÁRIA DE CORTE, 4., 1996, Piracicaba. Anais... Piracicaba: Fundação de Estudos Agrários “Luis de Queiroz”, 1997.

FORREST, J.C.A.; ABERLE, E.D.A.; HEDRICK, H.B. et al. Principles of meat science. S.l.: W. H. Freeman and Company, 1975. 417p.

FOX, D.G.; SNIFFEN, C.J.; O'CONNOR, J.D. et al. Search: agriculture. Ithaca: Cornell University Agriculture Experimental Station, n.34, 1992. 128p.

FRANCO, G. Tabela de composição química dos alimentos. 9.ed. São Paulo: Atheneu, 2001. 307p.

FRENCH, P.; STANTON, C.; LAWLESS, F. et al. Fatty acid composition, including conjugated linoleic acid, of intramuscular fat from steers offered grazed grass silage, or concentrate-based diets. Journal of Animal Science, v.78, p.2849-2855, 2000.

HENDERSON, C. The effects of fatty acids on pure cultures of rumen bacteria. Journal of Agricultural Science, v.81, p.107, 1973.

JENKINS, T.C. Symposium: advances in ruminant lipid metabolism. Lipid metabolism in the rumen. Journal of Dairy Science, v.76, p.3851, 1993.

JOHNSON, R.R.; McLURE, K.E. High fat rations for ruminants. II. Effects of fat added to corn plant material prior to ensiling on digestibility and voluntary intake of the silage. Journal of Animal Science, v.36, p.397, 1973.

LUCHIARI FILHO, A. Pecuária da carne bovina. São Paulo: A. Luchiari Filho, 2000. 134p.

MAY, S.G.; DOLEZAL, H.G.; GILL, D.R.S. et al. Effects of days fed, carcass grade traits, and subcutaneous fat removal on post mortem muscle characteristics and beef palatability. Journal of Animal Science, v.70, p.444-453, 1992.

MEDEIROS, S.R. Curso sobre valor nutritivo dos alimentos e análise bromatológica para ruminantes. Módulo 4Gordura. 2002. 10 p. (Apostila)

MOLETTA, J.L. Utilização de soja grão ou caroço de algodão, na terminação de bovinos de corte em confinamento. In: REUNIÃO ANUAL DA SOCIEDADE BRASILEIRA DE ZOOTECNIA, 36., 1999, Porto Alegre. Anais... São Paulo: Gnosis, 1999. 1 CD.

NGIDI, M.E.; LOERCH, S.C.; FLUHARTY, F.L. et al. Effects of calcium soaps of long-chain fatty acids on feedlot performance, carcass characteristics and ruminal metabolism of steers. Journal of Animal Science, v.68, p.2555, 1990 .

PAGE, A.M.; STURDIVANT, C.A.; LUNT, D.K. et al. Dietary whole cottonseed depresses lipogenesis but has no effect on stearoyl coenzyme desaturase activity in bovine subcutaneous adipose tissue. Comparative Biochemistry Physiology, v.118B, n.1, p.79-84, 1997.

PAULINO, M.F.; DETMANN, E.; VALADARES FILHO, S.C. et al. Soja grão e caroço de algodão em suplementos múltiplos para terminação de bovinos mestiços em pastejo. Revista Brasileira de Zootecnia, v.31, n.1, p.484-491, 2002 (Suplemento).
PRADO, I.N.; BRANCO, A.F.; ZEOULA, L.M. et al. Desempenho e características de carcaça de bovinos Nelore confinados, recebendo 15 ou 30\% de caroço integral de algodão, bagaço auto-hidrolisado de cana-de-açúcar ou capim elefante. Arquivos de Biologia e Tecnologia, v.38, n.2, p.353-365, 1995.

PUTRINO, S.M. Exigências de proteína e energia líquidas para o ganho de peso de tourinhos das raças Nelore e Brangus alimentados com dietas com diferentes proporções de concentrado. Pirassununga: Universidade de São Paulo, 2002. 82p. Dissertação (Mestrado em Zootecnia) Universidade de São Paulo, 2002.

RUY, D.C.; LUCCI, C.S.; MELOTTI, L. et al. Degradação da proteína e fibra do caroço de algodão integral (Gossypium hirsutum L.) no rúmen. Brazilian Journal of Veterinary Research and Animal Science, v.33, p.276-280, 1996. Suplemento.

SALLES, M.S.V.; LEME, P.R.; ZANETTI, M.A. et al. Avaliação dos efeitos do caroço de algodão e gordura protegida nos parâmetros ruminais de bovinos em terminação arraçoados com alto nível de concentrado. In: REUNIÃO ANUAL DA SOCIEDADE BRASILEIRA DE ZOOTECNIA, 40., 2003, Santa Maria. Anais... Santa Maria: Infovia, 2003. 1 CD.

SILVA, D.J. Análise de alimentos: métodos químicos e biológicos. Viçosa, MG: Universidade Federal de Viçosa, 1998. 166p.

SILVA, S.L. Estimativa de características de carcaça e ponto ideal de abate por ultra-sonografia, em bovinos submetidos a diferentes níveis energéticos na ração. Pirassununga: Universidade de São Paulo, 2002. 65p. Dissertação (Mestrado) - Universidade de São Paulo, 2002.

SUTTER, F.; CASUTT, M.M.; OSSOWSKI, D.A. et al. Comparative evaluation of rumen-protected fat, coconut oil and various oilseeds supplemented to fattening bulls. 1. Effects on growth, carcass and meat quality. Archives of Animal Nutrition, v.53, p.1-23, 2000.

SWENSON, M.J.; REECE, W. Dukes fisiologia dos animais domésticos. 11.ed. Rio de Janeiro: Guanabara, 1996. 856p.

TUME, R. Environmental factors on fatty acid composition and its impact on the assessment of marbling. Disponível em : http://www.beef.crc.org.au/Publicatoins/MarblingSym/ Day1/Rtume/index1.html/. Acesso em: 04 fev. 2003.

VALADARES, R.F.D.; GONÇALVES, L.C.; RODRIGUEZ, N.M. et al. Níveis de proteína em dietas de bovinos. 4. Concentração de amônia ruminal e uréia plasmática e excreções de creatinina. Revista Brasileira de Zootecnia, v.26, n.6, p.1270-1278, 1997.

VALINOTE, A.C.; NOGUEIRA FILHO, J.C.M.; LEME, P.R. et al. Effect of source monensin on ciliate protozoa in the rumen of Nellore steers. Tropical and Subtropical Agrosystems, Mexico, p.151-154, 2003.

WEISS, W.P.; CONRAD, H.R.; PIERRE, N.R. A theoreticalbased model for predicting total digestible nutrient values of forages and concentrates. Animal Feed Science Technology. Amsterdan, 39: 95-110, 1992.

ZINN, R.A.; GULATI, S.K.; PLASCENCIA, A. et al. Influence of ruminal biohydrogenation on the feeding value of fat in finishing diets for feedlot cattle. Journal of Animal Science, v.78, p.1738-1746, 2000. 